\title{
URETERAL STENOSIS OF TRANSPLANTED KIDNEY
}

\author{
Mikiusica J ${ }^{1}$, Dedinska $I^{1}$, Palkoci B ${ }^{1}$, Fialova $J^{1}$, Osinova $D^{2}$, VoJTKo M $^{1}$, LaCa L ${ }^{1}$. \\ ${ }^{1}$ Comenius University, Jessenius Faculty of Medicine and University Hospital Martin, Surgery Clinic \\ and Transplant Center, Martin, Slovakia \\ ${ }^{2}$ Comenius University, Jessenius Faculty of Medicine and University Hospital Martin, Department of \\ Anesthesiology and Intensive Medicine, Martin, Slovakia
}

\begin{abstract}
Introduction: Ureteral stenosis is one of the most commonly reported urological complications after kidney transplantation.

Material and methods: This is a retrospective analysis of the risk factors for ureteral stenosis (type of donor, age of donor, presence of interior polar arteria, unilateral dual transplantation, diabetes mellitus of the recipient and the donor, BK positivity, child recipient, cold ischaemia time, and delayed graft function), as well as the causes and types of treating ureteral stenoses.

Results: In the group of 278 patients, the occurrence was $7.2 \%$. The medial of occurrence of ureteral stenoses was 24.6 months. The independent risk factor for ureteral stenosis in our group was the age of the donor $\geq 70$ years [HR 6.5833; 95 \% CI 2.2448-19,3070 ( $\mathrm{P}=0.0006)$ ], BK positivity [HR 13.6667; $95 \%$ CI 6.9127-27.0196 ( $<<0.0001)$ ], cold ischaemia time > $1080 \mathrm{~min}$ [HR 4.0368; $95 \%$ CI 1.7250-9,4465 ( $=0.0013)$ ], and diabetes mellitus in the donor's history [HR 16.2667; 95 \% CI 7.8629-33.6525 (P <0.0001)]. The most frequent type of treating the ureteral stenosis in our group was retroureteroneocystostomy. After surgical treatment, we recorded no recurrence of stenosis.

Conclusion: In our analysis, the confirmed independent risk factor was diabetes mellitus of the donor. However, further monitoring and analyses of large groups of patients are necessary. Surgical treatment of ureteral stenosis is safe. However, the most important momentum in surgical treatment of ureteral stenosis still remains the surgeon's experience in the given type of treatment.
\end{abstract}

Key words: ureteral stenosis, kidney transplantation, retroureteroneocystostomy, pelveureteroanastomosis, BK virus

\section{INTRODUCTION}

Approximately $1 \%-4.5 \%$ of renal transplant recipients will develop ureteral stenosis at sometimes after surgery (1). Ureteral stenosis is one of the most commonly reported urological complications after kidney transplantation often occurring within the first 3 months after surgery (2). Distal stenosis is most common. Ureteral devascularization leading to intrinsic stricture formation is the principle cause in nearly $90 \%$ cases (3). Technical errors during ureteroneocystostomy, extrinsic compression (e.g. hematoma, lymphocele, abscess), kinking of a redundant ureter, collecting system hematoma, a stone transplanted with the kidney, and anastomotic edema can because of ostenosis during the early postoperative ( $<3$ months) period. Late stenosis (>3 months) usually results from ureteral ischemia, but vasculitis secondary to acute rejection, lymphocele, fibrosis from immunosuppressive medications, and ureterolithiasis may also occur (4).

The risk factors for development of ureteral stenosis may be divided to surgical factors, factors on side of the donor, and factors on side of the recipient - table $1(5,6,7)$.

\footnotetext{
Address for correspondence:

Doc. MUDr. Ivana Dedinská, PhD., Surgery Clinic and Transplant Center University Hospital Martin,

Kollárova Str. N. 2, 03601 Martin, Slovak Republic; e-mail: idedinska@yahoo.co.uk; phone: +421 434203 920; fax number: +421434230131
} 
Tab. 1 Risk factors for development of ureteral stenosis

\begin{tabular}{|l|l|}
\hline Risk factors of ureteral stenosis & $\begin{array}{l}\text { Excessive dissection in the ,gold triangle“ area } \\
\text { Insufficient surgery technique } \\
\text { Unilateral dual transplantation }\end{array}$ \\
\hline On side of the donor & $\begin{array}{l}\text { Higher age } \\
\text { Inferior polar artery } \\
\text { Dead donor }\end{array}$ \\
\hline On side of the recipient & $\begin{array}{l}\text { Diabetes mellitus } \\
\text { BK nephropathia } \\
\text { Child recipient }\end{array}$ \\
\hline Other & $\begin{array}{l}\text { Extended cold ischaemia time } \\
\text { Delayed graft function }\end{array}$ \\
\hline
\end{tabular}

Early diagnosis and treatment are crucial for the safe continuity of the graft functions (8).

There are several imaging modalities that can be used to diagnose and assess hydronephrosis, including ultrasonography, CT, MR urography and scintigraphy. Ultrasonography is the ideal risk-free first-line investigation, providing a sensitive tool for confirming hydronephrosis, excluding periureteric collections and ensuring normal transplant perfusion, but hydronephrosis may only be minimal in the early stages (3). Once ureteral stenosis is confirmed or strongly suspected, urinary diversion must be undertaken promptly to minimize kidney damage. This is best achieved by percutaneous nephrostomy insertion. Although retrograde stent insertion may be used, this can be technically challenging, as the ureteric anastomosis is routinely performed along the anterolateral bladder wall, making it difficult to access and manipulate with endoscopic approach. Surgical intervention is indicated if minimum invasive procedures fail. Options include ureteroneocystostomy with excision of the stenotic segment and reimplantation or ureteroureterostomy using the recipient ipsilateral ureter (pyeloureterostomy between the donor renal pelvis and recipient ureter) (3).

In our center, in case of diagnostics of ureteral stenosis, we make the attempt for retrograde insertion of a stent. In the event it is impossible to make retrograde insertion of the stent to ureter, we realise surgery with implantation of the native ureter with pelveoureteroanastomosis or reimplatation of ureter by reureteroneocystostomy.

\section{MATERIAL AND METHODS}

The retrospective analysis contains the patients after kidney transplantation realised in the Transplant Center in Martin during the period 06/2003 - 08/2016. In the recipients, we discovered presence of ureteral stenosis (early and late) and we identified the individual risk factors for development of ureteral stenosis (type of donor, age of donor, presence of interior polar artery, unilateral dual transplantation, diabetes mellitus of the recipient and the donor, BK positivity, child recipient, cold ischaemia time, and delayed graft function). In the next analysis, we evaluated the type of treatment in the group of patients with diagnosed ureteral stenosis. We also discovered the cause of stenosis. We used a certified statistical program MedCalc version 13. 1. 2. for statistical evaluation and we used the following statistical analyses: correlation coefficient, Logistic regression, Cox's regression analysis. We consider the value $\mathrm{P}<0.05$ to be statistically significant. 
Compliance with Ethical Standards: The authors declare no conflicts of interest.

Ethical approval: All procedures performed in studies involving human participants are approved with the ethical standards of the institutional and/or national research committee and with the 1964 Helsinki Declaration and its later amendments or comparable ethical standards.

\section{RESULTS}

The group was composed of 278 patients after kidney transplantation, including 260 patients who underwent kidney transplantation from post mortem donor (93.5\%), and we diagnosed ureteral stenosis in 20 patients (7.2\%) - set characteristisc are shown in Table 2.

Tab. 2 Set characteristics

\begin{tabular}{|c|c|c|c|}
\hline & $\begin{array}{c}\text { no stenosis } \\
(\mathrm{n}=258)\end{array}$ & $\begin{array}{l}\text { stenosis } \\
(\mathrm{n}=20)\end{array}$ & $P$ value \\
\hline Sex of the donor (males) (\%) & 66.3 & 80 & 0.2902 \\
\hline Age of the donor (years) & $44 \pm 15$ & $51 \pm 13$ & 0.0435 \\
\hline Weight of the donor $(\mathrm{kg})$ & $75.4 \pm 18.1$ & $81.7 \pm 18$ & 0.1347 \\
\hline Type of collection (MO) (\%) & 55.4 & 20 & 0.0023 \\
\hline Type of the donor (ECD) (\%) & 23.6 & 40 & 0.1023 \\
\hline Inferior polar artery (\%) & 12 & 15 & 0.6936 \\
\hline Arterial hypertension of the donor (\%) & 26.7 & 40 & 0.2010 \\
\hline Diabetes mellitus of the donor (\%) & 1.6 & 20 & 0.0073 \\
\hline $\begin{array}{l}\text { Age of the recipient at the time of } \mathrm{KT} \\
\text { (years) }\end{array}$ & $47 \pm 11.5$ & $50 \pm 11.2$ & 0.2612 \\
\hline Sex of the recipient (males) (\%) & 59.7 & 60 & 0.9790 \\
\hline UK stent (\%) & 71.3 & 65 & 0.5511 \\
\hline Diabetes mellitus of the recipient (\%) & 15.9 & 10 & 0.4830 \\
\hline BKV positivity (\%) & 1.6 & 40 & $<0.0001$ \\
\hline CIT (min) & $720 \pm 335$ & $878.2 \pm 236.4$ & 0.0393 \\
\hline DGF (\%) & 27.5 & 10 & 0.0871 \\
\hline Dual transplantation (\%) & 1.6 & 0 & 0.5694 \\
\hline
\end{tabular}

Legend: MO - multi organ collection; ECD - extended criteria donor; KT - kidney transplantation; BKV BK virus; CIT - cold ischaemia time; DGF - delayed graft function

The median of development of ureteral stenoses was 24.6 months. Early stenosis was diagnosed in 5 patients, late stenosis was diagnosed in 15 patients. The predictor for development of ureteral stenosis in our group was: history of diabetes mellitus of the donor, BK positivity (viruria or viremia), and cold ischaemia time (table 3). 
Tab. 3 Logistic regression

\begin{tabular}{|l|c|c|c|}
\hline & Odds ratio & 95 \% CI & P value \\
\hline Sex of the donor (males) & 1.2121 & $0.3634-4.0425$ & 0.7513 \\
Age of the donor & 1.0252 & $0.9891-1.0626$ & 0.1536 \\
Weight of the donor & 1.0235 & $0.9904-1.0577$ & 0.1515 \\
Type of collection (MO) & 2.2304 & $0.6715-7.4082$ & 0.1701 \\
Type of the donor (ECD) & 0.6374 & $0.1904-2.1332$ & 0.4104 \\
Inferior polar artery & 1.2706 & $0.2715-5,9459$ & 0.7628 \\
Arterial hypertension of the donor & 1.3576 & $0.4930-3.7384$ & 0.5564 \\
Diabetes mellitus of the donor (n=8) & 0.5580 & $0.3528-0.7631$ & $<0.0001$ \\
Age of the recipient at the time of KT & 1.0081 & $0.9617-1.0567$ & 0.7364 \\
Sex of the recipient (males) & 0.4219 & $0.1322-1.3467$ & 0.1461 \\
UK stent & 0.6752 & $0.5431-0.7892$ & 0.7752 \\
Diabetes mellitus of the recipient & 0.5397 & $0.1014-2.8730$ & 0.4518 \\
BKV positivity & 0.700 & $0.5693-0.8114$ & $<0.0001$ \\
CIT & 1.0042 & $1.0016-1.0067$ & 0.0002 \\
DGF & 0.7778 & $0.1371-4.4118$ & 0.7733 \\
Dual transplantation & 0.5121 & $0.3815-0.6426$ & 0.3703 \\
\hline
\end{tabular}

MO - multi organ collection; ECD - extended criteria donor; KT - kidney transplantation; BKV - BK virus; CIT - cold ischaemia time; DGF - delayed graft function

The predictor for development of early stenosis was only diabetes mellitus of the donors [OR 0.4561, 95\%CI 03535-0.7742, P <0.0001]. The independent risk factor for development of ureteral stenosis in our group was: age of the donor above 70 years, history of diabetes mellitus of the donor, BK positivity (viremia or viruria), and cold ischaemia time of more than 1080 min (table 4). 
Tab. 4 Cox's regression Hazard Model

\begin{tabular}{|c|c|c|c|}
\hline & Hazard ratio & $95 \% \mathrm{CI}$ & $P$ value \\
\hline Sex of the donor (males) & 1.5187 & $0.5256-4.3882$ & 0.4402 \\
\hline Age of the donor $\leq 49$ years $(n=146$ ) & 0.8682 & $0.3751-2.0095$ & 0.7414 \\
\hline Age of the donor $50-59$ years $(n=73)$ & 0.7671 & $0.2896-2.0320$ & 0.5938 \\
\hline Age of the donor $60-69$ years $(n=35)$ & 1.0387 & $0.3211-3.3597$ & 0.9495 \\
\hline Age of the donor $\geq 70$ years $(n=24)$ & 6.5833 & $2.2448-19,3070$ & 0.0006 \\
\hline Type of collection (MO) & 2.0625 & $0.6921-6.1468$ & 0.1938 \\
\hline Type of the donor (ECD) & 0.8994 & $0.3040-2.6610$ & 0.8481 \\
\hline Inferior polar artery & 1.1626 & $0.3597-3.7579$ & 0.8012 \\
\hline Arterial hypertension of the donor & 1.7001 & $0.7117-4.0611$ & 0.2323 \\
\hline Diabetes mellitus of the donor $(n=8)$ & 16.2667 & $7.8629-33.6525$ & $<0.0001$ \\
\hline Age of the recipient at the time of $K T \leq 49$ years & 0.7810 & $0.3350-1.8208$ & 0.5671 \\
\hline Age of the recipient at the time of KT $50-59$ years & 1.0959 & $0.4539-2.6459$ & 0.8386 \\
\hline Age of the recipient at the time of KT $60-69$ years & 1.3232 & $0.4660-3.7570$ & 0.5989 \\
\hline Sex of the recipient (males) & 0.8313 & $0.3526-1.9598$ & 0.6729 \\
\hline UK stent & 0.5751 & $0.2402-1.3765$ & 0.2141 \\
\hline Diabetes mellitus of the recipient & 0.5556 & $0.1338-2.3070$ & 0.4184 \\
\hline BK positivity & 13.6667 & $6.9127-27.0196$ & $<0.0001$ \\
\hline $\mathrm{CIT} \leq 360 \mathrm{~min}$ & 0.1684 & $0.01044-2.7175$ & 0.2093 \\
\hline CIT $360-720 \mathrm{~min}$ & 0.4273 & $0.1602-1.1395$ & 0.0893 \\
\hline CIT 720 - $1080 \mathrm{~min}$ & 0.8782 & $0.2694-2.8630$ & 0.8294 \\
\hline $\mathrm{CIT}>1080 \mathrm{~min}$ & 4.0368 & $1.7250-9,4465$ & 0.0013 \\
\hline DGF & 0.4952 & $0.1190-2.0598$ & 0.3338 \\
\hline Dual transplantation & 1.2439 & $0.08682-17.8220$ & 0.8723 \\
\hline
\end{tabular}

MO - multi organ collection; ECD - extended criteria donor; KT - kidney transplantation; BKV - BK virus; CIT - cold ischaemia time; DGF - delayed graft function

The development of ureteral stenosis was correlated to the age of the donor, presence of diabetes mellitus of the donor, and BK positivity (Table 5). 
Tab. 5 Correlation coefficient

\begin{tabular}{|l|c|c|c|}
\hline & Correlation coefficient & 95 \% CI & P value \\
\hline Sex of the donor (males) & 0.04881 & $-0.07376-0.1699$ & 0.4350 \\
Age of the donor & 0.1212 & $-0.0009886-0.2397$ & 0.0419 \\
Weight of the donor & 0.09266 & $-0.03889-0.2211$ & 0.1670 \\
Type of collection (MO) & 0.08387 & $-0.03938-0.2046$ & 0.1818 \\
Type of the donor (ECD) & 0.08101 & $-0.04153-0.2011$ & 0.1946 \\
Inferior polar artery & 0.01561 & $-0.1067-0.1375$ & 0.8029 \\
Arterial hypertension of the donor & 0.07490 & $-0.04790-0.1955$ & 0.2314 \\
Diabetes mellitus in the donor & 0.5173 & $0.4214-0.6017$ & $<0.0001$ \\
Age of the recipient at the time of KT & 0.06881 & $-0.05377-0.1893$ & 0.2708 \\
Sex of the recipient (males) & -0.02627 & $-0.1479-0.09616$ & 0.6745 \\
UK stent & -0.07748 & $-0.1977-0.04507$ & 0.2148 \\
Diabetes mellitus of the recipient & -0.05186 & $-0.1729-0.07072$ & 0.4069 \\
BKV positivity & 0.4866 & $0.3875-0.5746$ & $<0.0001$ \\
CIT & -0.05860 & $-0.1811-0.06570$ & 0.3552 \\
DGF & -0.06333 & $-0.1857-0.06097$ & 0.3176 \\
Dual transplantation & -0.03638 & $-0.1578-0.08613$ & 0.5608 \\
\hline
\end{tabular}

MO - multi organ collection; ECD - extended criteria donor; KT - kidney transplantation; BKV - BK virus; CIT - cold ischaemia time; DGF - delayed graft function

Figure 1 shows the causes of ureteral stenosis in our group. In our group, the most frequent was fibrosis (as histologic finding) and BK virus.

Fig. 1 Shares of patients with ureteral stenosis in the group according to the cause

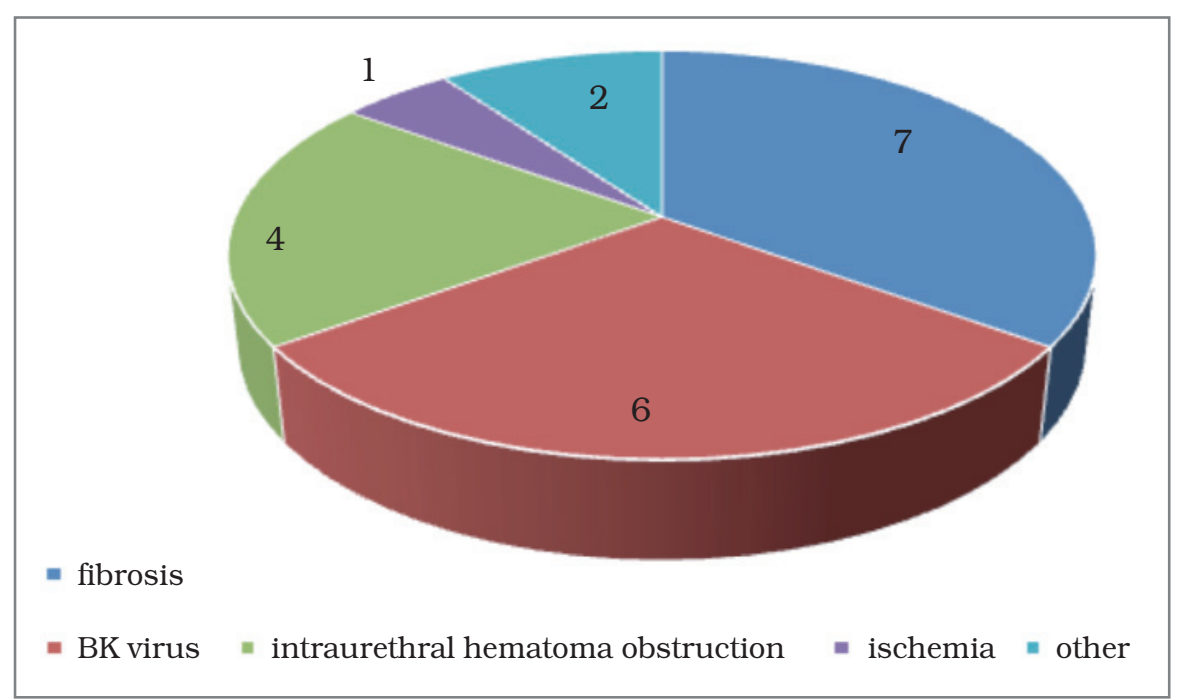


In the end, we realised the analyses according to the type of treatment of ureteral stenosis (Fig. 2). Retroureteroneocystostomy (extravesical) was performed in $55 \%$.

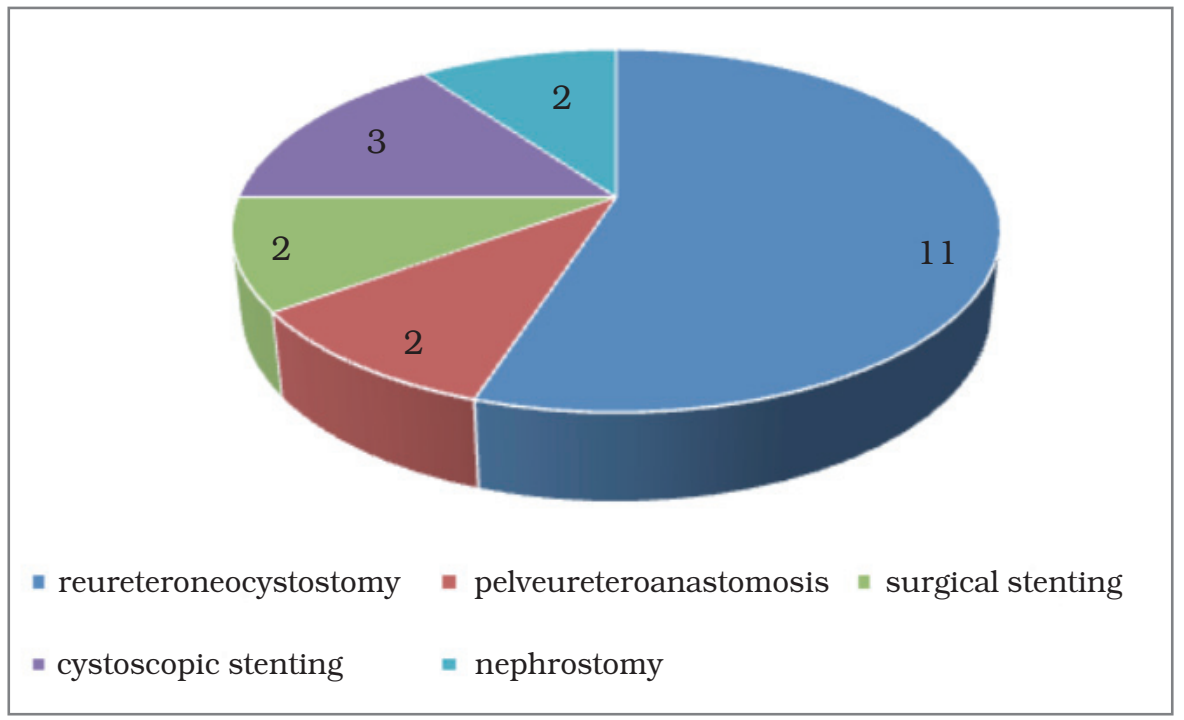

Fig. 2 Shares of patients with ureteral stenosis in the group according to the type of treatment

2 patients underwent pelveureteroanastomosis. After surgical treatment, we recorded no recurrence of ureteral stenosis in the patients.

All cases of ureteral stenosis in our group were diagnosed by sonography. In each patient, we recorded also slightly impaired function of the graft $(\mathrm{P}=0.2384)$ with gradual adjustment of creatinine to the original values before diagnosis of ureteral stenosis (Fig. 3).

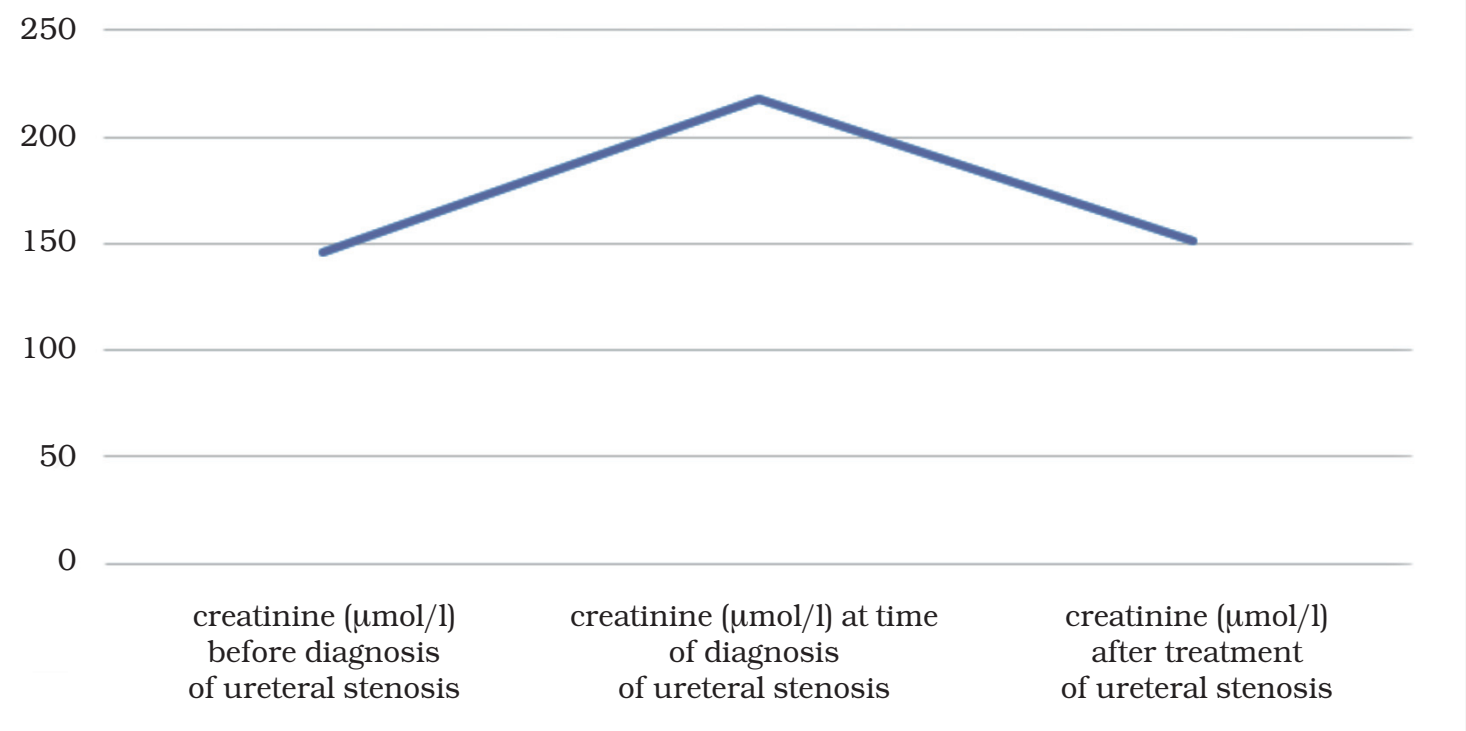

Fig. 3 Development of the value of creatinine in the patients with ureteral stenosis 


\section{DISCUSSION}

The development of ureteral stenosis in our group was $7.2 \%$ diagnosed by ultrasonography (hydronephrosis). Higher incidence of hydronephrosis in our set of patients might be cause by reflux only. In the group of patients in the retrospective analysis of the authors Martino et al. it was $2.76 \%$. In 2002. Streeter and colleagues reported an overall major urologic complication rate of $9.2 \%$ following 1535 consecutive renal transplants (1). Ureteral complications were most common with urine leak and stenosis occurring in $2.9 \%$ and $3.0 \%$ of recipients, respectively. A more recent series of 1670 consecutive transplants published in 2015 found a urologic complication rate of $8 \%$. Urine leak occurred in $1.8 \%$ men and $4 \%$ women, while ureteral stricture formation was observed in $2.4 \%$ male and $1.2 \%$ female recipients (9). We assume that the slightly higher incidence of ureteral stenosis in our group, compared with the available literature, is related to frequent ultrasonographic check-up of grafts in the post-transplantation period.

In our group, we identified the following independent risk factors for development of ureteral obstruction: BK viruria or viremia, age of the donor above 70 years, cold ischaemia time (more than 1080 minutes), and diabetes mellitus of the donor. The first association of BK with ureteral stenosis was in these minal 1971 publication reporting isolation of a new virus, BK, named for the initials of the first patient who presented three months after transplant with obstructive uropathy. It remains uncertain whether BK virus is the primary cause of ureteric stenosis or whether BK virus infects previously injured ureter (from ischemia or other trauma) as a secondary insult (10).

In the retrospective analysis of 421 patients after Stem Cell Transplantation, the authors identified six patients who demonstrated a significant increase in creatinine level (i.e. doubling from base line levels) or a >50 \% decrease in creatinine clearance underwent evaluation for obstructive uropathy and had a temporary nephrostomy catheter placed to relieve stenosis (11). However, no systematic analyses or prospective study with clear correlation of $\mathrm{BK}$ viremia or viruria is found in the available literature. However, we repeat that by the form of casuistics, the relationship between ureteral stenosis and BK positivity was confirmed. The mentioned study by the authors Streeter et al. confirm the significant difference between the donor's age of the patients with ureteral stenosis and the donor's age of the recipients in which no ureteral stenosis was developed $(\mathrm{P}<0.05)(1)$. In another study by the authors Karam et al. with more than 1700 patients, the donor's age more than 65 years correlated with development of ureteral stenosis $(P=0.001)(12)$. In the study with 1450 patients after kidney transplantation, there was no association between the gender and the ischemic time; source of the allograft and ischemic time; size of stricture and source of the allograft; and ischemic time and age (13). However, the prolonged cold ischemia time is identified by several authors as one of the basic risk factors for ureteral stenosis (14). The interesting finding of our analysis is identification of diabetes mellitus of the donor as a risk factor for ureteral stenosis. The available literature contains no information about association between ureteral stenosis and diabetes mellitus of the donor. The presumption for our results may be the theory of presence of frequent infections of urinary tract of the donor with diabetes mellitus.

Ureteral stenosis have been traditionally managed by open ureteroneocystostomy or more complex reconstructive procedures. In select cases, endourologic techniques have been utilized in the effort to spare patients the potential morbidity of open reconstruction $(4,15)$. In our group, the majority of ureteral stenoses were treated by surgery - retroureteroneocystostomy or pelveureteroanastomosis. Neither of such treated patients had recurrence of stenosis. The surgical techniques represent a preferred method in our center, because they represent final solution of stenosis and low risk of infectious complications (long-term insertion of stent or nephrostomy). 


\section{CONCLUSION}

In our analysis we confirmed that the independent risk factors for ureteral stenosis are the age of the donor above 70 years, BK positivity, and prolonged cold ischaemia time. Diabetes mellitus of the donor was also confirmed in our analysis as an independent risk factor. Further monitoring and analyses in large groups of patients are necessary. In our group, the treatment of ureteral stenosis was mostly surgery (retroureteroneocystostomy or pelveureteroanastomosis), with no recurrence of stenosis and without any additional post-operative complications. However, the most important moment in the surgical treatment of ureteral stenosis is still the surgeon's experience in the given type of surgery.

\section{REFERENCES}

1. Streeter EH, Little DM, Cranston DW, Morris PJ. The urological complications of renal transplantation: a series of 1535 patients. BJU Int 2002; 90: 627-634.

2. Martino P1. Impedovo SV, Palazzo S, et al. Ureteral strictures after kidney transplantation: risk factors. ArchItal Urol Androl 2012; 84(4):287-90.

3. Kumar S, Ameli-Renani S, Hakim S, et al. Ureteral obstruction following renal transplantation: causes, diagnosis and management. Br J Radiol 2014; 87 (2014) 20140169

4. Duty BD, Barry JM. Diagnosis and management of ureteral complications following renal transplantation. AsianJournal of Urology 2015; 2(4): 202-207.

5. Pereira G, Buchler M, Brichart N, et al. Ureteral stenosis after renal transplantation: Risk factors and impact on survival. ProgUrol 2011; 21(6): 389-396.

6. Dalgic A, Boyvat H, Karakayali H, et al. Urologic Complications in 1523 Renal Transplantations: The Baskent University Experience. Transplantation Proceedings 2006; 38 (2): 543-547.

7. Dinckan A, Tekin A, Turkyilma S, et al. Early and late urological complications corrected surgically following renal transplantation. Transplant International 2007; 20 (8): 702-707.

8. Gökçe AM, Kaya C, Kara VM, et al. Effects of Urethral Stricture on Allografts in Kidney Transplantation. Transplant Proc 2015; 47(5):1336-9.

9. Lempinen J, Stenman J, Kyllonen L, Salmela K. Surgical complications following 1670 consecutive adult renal transplantations: a single center study. Scand J Surg2015;104(4):254-9.

10. Gardner SD, Field AM, Coleman DV, Hulme B. New human papovavirus (B.K.) isolated from urine after renal transplantation. Lancet 1971;1(7712):1253.

11. Khan H, Oberoi S, Mahvash A, et al. Reversible Ureteral Obstruction due to Polyomavirus Infection after Percutaneous Nephrostomy Catheter Placement. Biology of Blood and Marrow Transplantation $2011 ; 17(10):$ 1551-1555.

12. Karam G, Hétet JF, Maillet F, et al. Late Ureteral Stenosis Following Renal Transplantation: Risk Factors and Impact on Patient and Graft Survival 2006; 6(2): 352-356.

13. Mahdavi Zafarghandi R, Sheikhi Zh. Extensive Ureteral Stricture in Renal Transplant Recipients: Prevalence and Impact on Graft and Patient Survival. Int J Organ Transplant Med. 2013; 4(4): $165-171$.

14. Giessing M. Transplant ureter stricture following renal transplantation: surgical optionsTransplant Proc 2011; 43: 383-386.

15. Prídavková D, Kantárová D, Červeň P, et al. Obezita a obvod krku - "starý" nový parameter kardiometabolického rizika. Diabetes a obezita 2015; 15(30): 91-97.

Received: May, 9, 2017

Accepted: July, 13, 2017 